\title{
A Teoria do Discurso de Laclau e Mouffe e a Pesquisa em Educação
}

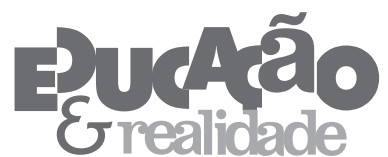

Gustavo Gilson Oliveira'

Anna Luiza Oliveira'

Rui Gomes de Mesquita'

\author{
'Universidade Federal de Pernambuco (UFPE), Recife/PE - Brasil
}

\begin{abstract}
RESUMO - A Teoria do Discurso de Laclau e Mouffe e a Pesquisa em Educação. O artigo desenvolve uma discussão teórico-metodológica sobre as possibilidades e condições para a articulação de abordagens pós-estruturalistas, especialmente da Teoria do Discurso de Laclau e Mouffe, na realização de pesquisas empíricas em educação. Inicialmente, é delineada uma breve revisão conceitual sobre a ontologia pós-estruturalista e sobre suas consequências quanto à rejeição do positivismo e da epistemologia moderna. A seguir, são apresentadas e analisadas quatro proposições formuladas por Glynos e Howarth para a realização de pesquisas referenciadas na teoria do discurso. Por fim, é resgatado o debate sobre a exigência de rigor analítico e sobre o potencial crítico dessa teoria na realização de pesquisas no campo da Educação.

Palavras-chave: Teoria do Discurso. Pesquisa em Educação. Metodologia da Pesquisa. Epistemologia. Pós-estruturalismo.
\end{abstract}

ABSTRACT - The Discourse Theory of Laclau and Mouffe and Research in Education. The paper develops a theoretical and methodological discussion about the possibilities and conditions for the articulation of poststructuralist approaches in conducting empirical research in education, especially regarding the Discourse Theory of Laclau and Mouffe. Initially it presents a short conceptual review of the poststructuralist ontology and of their consequences for the rejection of positivism and of modern epistemology. The following are presented and analyzed four propositions formulated by Glynos and Howarth for conducting research referenced in discourse theory. Finally, we rescued the debate on the need of analytical rigor and on the critical potential of this theory in conducting research in the field of Education.

Keywords: Discourse Theory. Educational Research. Research Methodology. Epistemology. Poststructuralism.

Educação \& Realidade, Porto Alegre, v. 38, n. 4, p. 1327-1349, out./dez. 2013. 
A Teoria do Discurso de Laclau e Mouffe e a Pesquisa em Educação

A partir de meados da década de 1990 uma parte significativa das pesquisas produzidas no campo da educação no Brasil começou a ser fortemente influenciada por autores, noções e concepções oriundos de correntes teóricas em ruptura com as tradições metanarrativas e universalistas modernas, correntes comumente denominadas como pósmodernas, pós-estruturalistas ou mesmo pós-críticas ${ }^{1}$ (Backes; Pavan, 2011; Paraíso, 2004; Silva, 1999). A redemocratização do país nos anos de 1980 e a crise das utopias e do socialismo real nos anos de 1990, entre outros fatores, contribuíram para a emergência e o reconhecimento, no contexto nacional, de diversas novas identidades, demandas, movimentos e atores sociais (feministas, negros, gays, ambientalistas, jovens da periferia, grupos culturais, religiosos etc.) que escapavam, em grande medida, ao alcance das ferramentas de análise social oferecidas pelas perspectivas tradicionais, predominantemente economicistas, classistas, institucionalistas e/ou funcionalistas. Também escapavam aos modelos culturalistas tradicionais que privilegiavam as análises de identidades e práticas culturais como fenômenos particulares e relativamente estáveis. Abordagens como a análise genealógica de Foucault, os estudos culturais, pós-colonialistas, feministas, queer e a teoria do discurso de Laclau e Mouffe forneceram aos analistas e pesquisadores do campo da educação recursos conceituais e interpretativos importantes para investigar até que ponto e como essas demandas e identidades se apresentam - mesmo que de forma marginal e/ou clandestina nos contextos educacionais. Como as práticas educativas estabelecidas contribuíram e contribuem para a sua negação, submissão e controle. Quais os movimentos e possibilidades de mudança social e transformação histórica abertos pela emergência e/ou reconhecimento desses novos atores e lógicas de atuação.

Apesar da fecundidade de questões e alternativas de análise possibilitadas pelas abordagens pós-estruturalistas, a tradução das intuições teóricas e analíticas em estratégias viáveis, consistentes e produtivas de investigação empírica continua a ser um desafio para muitos que começam a desenvolver pesquisas na área da educação e em áreas afins. A complexidade da crítica epistemológica pós-estruturalista afasta muitos pesquisadores iniciantes e faz com que outros incorporem parte de seu discurso e de sua linguagem sem, contudo, compreenderem profundamente as implicações ontológicas e metodológicas de seus pressupostos. Não é incomum encontrar trabalhos em que concepções e argumentos antimetafísicos e antiessencialistas são desenvolvidos em paralelo com modelos deterministas de testes de hipóteses causais, com distinções ingênuas entre a representação teórica e a realidade em si mesma ou com propostas simplistas de aplicação de métodos ou técnicas sobre um objeto de estudo, pretensamente exterior e claramente delimitado. Alguns esforços para tornar os debates epistemológicos e metodológicos das perspectivas pós-estruturalistas mais acessíveis a pesquisadores no campo da educação, especialmente a partir de uma perspectiva foucaultiana, já vem sendo realizados por

1328 Educação \& Realidade, Porto Alegre, v. 38, n. 4, p. 1327-1349, out./dez. 2013. Disponível em: <http://www.ufrgs.br/edu_realidade> 
autores como Veiga-Neto (2004), Costa (2007; 2002), Costa; Bujes (2005). Trabalhos como os de Lopes (2012; 2006), Lopes; Macedo (2011), Lopes; Oliveira (2011), Burity (2010), Southwell (2008); Macedo (2006) também já vêm buscando uma aproximação entre a teoria pós-estruturalista do discurso e a educação, sobretudo no âmbito dos estudos curriculares. Este artigo busca contribuir para o mesmo debate apresentando algumas considerações sobre a articulação da teoria do discurso de Ernesto Laclau e Chantal Mouffe (Laclau; Mouffe, 2001; 2000) na realização de pesquisas empíricas em ciências sociais e educação. Inicialmente, é delineada uma breve revisão sobre a ontologia pós-estruturalista, na perspectiva de Laclau e Mouffe, sobre suas consequências quanto à rejeição do positivismo e da epistemologia moderna. A seguir, são apresentadas e analisadas quatro proposições desenvolvidas por Jason Glynos e David Howarth (Glynos; Howarth, 2007) para a realização de pesquisas referenciadas na teoria do discurso. Por fim, é realizada uma discussão sobre o rigor analítico e o potencial crítico da teoria do discurso para as pesquisas no campo da educação.

\section{Ontologia Pós-estruturalista e a Crítica (anti)epistemológica}

Uma das principais dificuldades em adotar uma perspectiva pós-estruturalista na análise empírica de fenômenos sociais, inclusive no campo da educação, está associada ao fato de que a articulação coerente dessa abordagem implica, necessariamente, na realização de uma (auto)crítica sobre a própria concepção epistemológica de empiria dominante nas ciências modernas. Em grande medida, a virada epistemológica que caracteriza e lastreia o surgimento da própria noção de ciência, em seu sentido moderno, fundamenta-se na busca de um “[...] acesso imediato às coisas mesmas" (Laclau 2005, p. 80), ou seja, do conhecimento de uma objetividade extradiscursiva que vem a ser problematizada pelo pós-estruturalismo. A teoria pós-estruturalista do discurso, nesse sentido, rejeita radicalmente a possibilidade de tal acesso e afirma vigorosamente que não só o conhecimento, mas a própria realidade investigada pela ciência é produzida discursivamente, que é inevitavelmente atravessada pelos condicionantes e mecanismos próprios do campo simbólico e político da linguagem. A chamada mediação discursiva, portanto, não é um problema epistemológico como tem sido compreendida mesmo por algumas abordagens construcionistas (Madill, 2000). A discursividade é uma condição ontológica de constituição de todo o objeto e de toda a realidade experienciada pelos sujeitos. Para muitos críticos, essa perspectiva implicaria fatalmente numa postura idealista e excessivamente relativista, que seria incompatível com a ciência e, sobretudo, com a pesquisa empírica. Laclau e Mouffe (1989), todavia, contestam essa objeção indicando que:

O fato de que todo objeto seja constituído como um objeto de discurso não tem qualquer relação com até que ponto

Educação \& Realidade, Porto Alegre, v. 38, n. 4, p. 1327-1349, out./dez. 2013. 
existe um mundo externo ao pensamento ou com a oposição realismo/idealismo. Um terremoto ou a queda de um tijolo é um evento que certamente existe, no sentido de que ele ocorre aqui e agora, independentemente de minha vontade. Mas, o quanto sua especificidade como objetos é construída em termos de "fenômenos naturais" ou como "expressões da ira de Deus" depende da estruturação de um campo discursivo. O que é negado não é que tais objetos existem externamente ao pensamento, mas, de fato, a afirmação distinta de que eles podem constituir a si mesmos como objetos fora de quaisquer condições discursivas de emergência (Laclau; Mouffe, 1989, p.108).

A rejeição do pressuposto positivista de que o uso estrito de uma metodologia pré-estabelecida e generalizada poderia garantir a objetividade do conhecimento científico veio a produzir dois efeitos importantes nos estudos pós-estruturalistas e, especialmente, nos estudos inspirados pela teoria do discurso. O primeiro efeito, que pode ser considerado positivo, é que tais estudos sempre buscaram construir sua abordagem ou metodologia a partir das características e da realidade contextual do problema a ser defrontado, e não vice-versa. O segundo efeito, entretanto, é a relativa escassez de reflexões metodológicas explícitas e sistemáticas nesses estudos, mesmo considerando que muitos dos autores considerados pós-estruturalistas tenham se dedicado diretamente à análise de problemas empíricos² ${ }^{2}$ O mesmo ocorre com a maioria dos autores que trabalham com a teoria do discurso na perspectiva pós-estruturalista. Essa carência de reflexão metodológica explícita torna-se preocupante na medida em que dificulta uma utilização mais ampla e mais consistente dos recursos críticos e conceituais do pós-estruturalismo e da teoria do discurso nos trabalhos empíricos, na educação e nas ciências sociais em geral. Também na medida em que inibe o diálogo com outras tradições teórico-metodológicas de pesquisa e dificulta o desenvolvimento de critérios mais claros para a avaliação da qualidade das pesquisas, especialmente de orientação qualitativa. Esse tipo de fragilidade epistemológica já vem sendo discutida no campo da educação brasileira por trabalhos como os de Warde (1990), Cunha (1991), Gatti (1999 e 2001), André (2001) e Alves-Mazzotti (2001). Como observa Gatti (2001):

É fundamental o conhecimento dos meandros filosóficos, teóricos, técnicos e metodológicos da abordagem escolhida. Sob esse ponto, há também alguns problemas nos trabalhos de pesquisa na área educacional, tanto nos que usaram quantificação quanto nos que usaram metodologias alternativas. [...] encontram-se observações casuísticas, sem parâmetros teóricos, a descrição do óbvio, a elaboração pobre de observações de campo conduzidas com precariedade, análises de conteúdo realizados [sic] sem metodologia clara, incapacidade de reconstrução do dado e de percepção crítica de vieses situacionais, desco-

1330 Educação \& Realidade, Porto Alegre, v. 38, n. 4, p. 1327-1349, out./dez. 2013. Disponível em: <http://www.ufrgs.br/edu_realidade> 
nhecimento no trato da história e de estórias [sic], precariedade na documentação e na análise documental (Gatti, 2001, p. 75-76).

Uma nova geração de teóricos e analistas do discurso integrados aos debates metodológicos das ciências humanas vem buscando desenvolver uma reflexão mais sistemática sobre as implicações - e aplicações - da teoria do discurso na formulação de metodologias e na utilização de técnicas de produção e análise de dados nas pesquisas empíricas ${ }^{3}$. Parte do trabalho tem sido o de recuperar uma discussão sobre as características e opções metodológicas das pesquisas já realizadas no campo da - ou influenciadas pela - teoria pós-estruturalista do discurso. Embora esse movimento seja relativamente recente, já tem produzido alguns resultados importantes. Deve ser ressaltado, em primeiro lugar, que a teoria do discurso não consiste e não busca constituir-se em uma teoria geral da sociedade, dotada de uma taxonomia própria e de um conjunto de leis explicativas universais sobre o funcionamento ou a mudança social. A teoria do discurso é mais bem entendida como uma tradição de reflexões e debates que compartilham o mesmo referencial analítico e que, a partir desse referencial, buscam construir discursos contingentes e contextualizados sobre os processos sociais observados. Essa perspectiva, portanto, não se acomoda a um modelo de pesquisa que busque aplicar - partindo de uma pretensa exterioridade entre discurso subjetivo e mundo objetivo - certos conceitos abstratos gerais à realidade, como uma forma de confirmar ou refutar a teoria.

A teoria do discurso de Laclau e Mouffe, todavia, também é fortemente crítica em relação aos modelos positivistas clássicos de pesquisa que buscam extrair os dados da realidade e garantir sua validade através do uso estrito de uma metodologia reconhecida e supostamente neutra e universal. A abordagem de investigação mais condizente com as formulações da teoria do discurso - na concepção que vem sendo trabalhada até aqui - é a que autores como Shapiro (2002) vêm denominando pesquisa orientada ao problema [problem driven research], em oposição à pesquisa dirigida a partir da teoria ou do método. Essa abordagem, certamente, não deve implicar numa ausência de reflexões teóricas ou de rigor e seriedade metodológica, mas, numa elaboração em que a linha condutora do trabalho seja o enfrentamento do problema proposto, em que a teoria e a metodologia providenciem recursos para enriquecer e aprofundar a compreensão do problema e dos processos analisados.

Como propõe David Howarth (2005), a própria teoria deve ser observada como um discurso - intrinsecamente contingente - a ser articulado com os discursos sociais, o que também se constitui em um processo discursivo atravessado por relações agonísticas e de poder que devem ser reconhecidas e levadas em conta no trabalho do analista.

É evidente, todavia, que qualquer explanans plenamente desenvolvido contém uma pluralidade de diferentes tipos de lógicas e conceitos. Esses podem incluir lógicas e con-

Educação \& Realidade, Porto Alegre, v. 38, n. 4, p. 1327-1349, out./dez. 2013.1331 Disponível em: <http://www.ufrgs.br/edu_realidade> 
A Teoria do Discurso de Laclau e Mouffe e a Pesquisa em Educação

ceitos teoréticos como a lógica da fantasia lacaniana ou o conceito de iterabilidade derridiano; lógicas sociais mais concretas, tais quais a lógica do apartheid ou do mercado, que tem de ser construídas para dar conta de um conjunto particular de práticas sedimentadas; como também as lógicas políticas que têm estado envolvidas na constituição e contestação dessas lógicas sociais e fenômenos sob investigação. Como já foi sugerido, o problema quanto a essa questão diz respeito às condições sob as quais se é possível reunir esses elementos teoréticos e empíricos heterogêneos em uma cadeia explicativa sem reduzir ou subsumir tais elementos a leis ou abstrações de ordem maior, e sem abrir caminho para um ecletismo no qual lógicas e conceitos incompatíveis operam de um modo inconsistente (Howarth, 2005, p. 326).

Em seu livro Logics of Critical Explanation in Social and Political Theory, Glynos e Howarth (2007) procuraram desenvolver de modo sistemático uma reflexão sobre as implicações (anti)epistemológicas e metodológicas da teoria do discurso, buscando suprir o que alguns, como Torfing (2005), vinham identificando como um déficit metodológico no projeto teórico de Laclau e Mouffe (2001). Esse esforço resultou no delineamento de quatro proposições teórico-metodológicas para a realização de pesquisas empíricas referenciadas nessa perspectiva: i) A eleição de um modelo de pesquisa orientada ao problema [problem driven research], em oposição ao enfoque na metodologia ou na teoria; ii) A adoção de um modelo de ciclos de racionalidade retrodutiva como constituinte tanto da lógica da descoberta quanto da lógica da justificação nas ciências humanas e sociais; iii) A adoção do conceito de lógicas - sociais, políticas e fantasmáticas - como unidades explicativas para a interpretação dos fenômenos de formação, sustentação e mudança das identidades e práticas sociais; e iv) A utilização da perspectiva da articulação - em contraste com as noções de representação ou subsunção - como modelo de relação entre as categorias e formulações teóricas e analíticas e os demais significantes e discursos presentes no campo e/ ou enunciados pelos próprios sujeitos sociais. As indicações apresentadas estabelecem uma distinção clara entre o modelo de construção do conhecimento científico requerido pela concepção ontológica da teoria do discurso e os modelos epistemológicos (neo)positivistas ainda fortemente influentes na educação e nas ciências humanas. As proposições efetuadas por Glynos e Howarth (2007) são discutidas e analisadas, a seguir, buscando destacar seu sentido e suas possíveis contribuições para as pesquisas empíricas nos campos da educação e das ciências sociais no Brasil.

\section{A Pesquisa Orientada ao Problema}

A eleição de um modelo de pesquisa orientada ao problema implica que o elemento central a ser considerado nas decisões sobre as

1332 Educação \& Realidade, Porto Alegre, v. 38, n. 4, p. 1327-1349, out./dez. 2013 Disponível em: <http://www.ufrgs.br/edu_realidade> 
alternativas teoréticas e metodológicas escolhidas deve ser, no maior grau possível, o problema, definido a partir das demandas e crises concretas vivenciadas pelos sujeitos atuantes no campo investigado. Tal perspectiva, entretanto, não deve implicar em relativismo ou ecletismo superficial na escolha das vias teóricas ou da metodologia. As concepções ontológicas - e consequentemente epistemológicas - que substanciam a própria definição do problema precisam ser seriamente discutidas e, desse modo, explicitadas e articuladas coerentemente às alternativas teóricas e metodológicas. Essa articulação só pode ser coerente e defensável, todavia, na medida em que partir de e voltar-se para o enfrentamento dos problemas acusados e vivenciados pelos sujeitos sociais no contexto trabalhado. Do mesmo modo, a pesquisa orientada ao problema não deve ser interpretada como mais um exemplar de uma concepção puramente pragmática, imediatista ou ativista da pesquisa acadêmica. O papel da investigação, nessa perspectiva, não é o de construir panaceias, sanar contradições nos sistemas ou buscar soluções imediatas para problemas específicos, a proposta é ampliar a própria compreensão do problema de modo a reconhecer suas relações com as lógicas e processos sociais mais amplos, a demonstrar que qualquer solução para os problemas aparentemente pontuais passa por uma redefinição dos termos do próprio problema e por um deslocamento das condições que promovem sua emergência. Deve-se buscar evitar, desse modo, o imediatismo e o ativismo que Gatti (2001) identifica e critica severamente em relação às pesquisas em educação:

\begin{abstract}
O sentido pragmático e de um imediatismo específico observável nos estudos feitos na área da educacional refletese na escolha e na forma de tratamento dos problemas. Esses problemas, oriundos de práticas profissionais, são tratados, em geral, nos limites de um recorte academicista discutível em seus alcances. Além disso, a relação pesquisa-ação-mudança parece ser encarada de maneira um tanto simplista. Ainda que se reconheçam a necessária origem social dos temas e problemas na pesquisa em educação e a necessidade de trabalhos que estejam vinculados mais especificamente a questões que no imediato são carentes de análise e proposições, uma certa cautela quanto a essa tendência deveria ser tomada (Gatti, 2001, p. 70).
\end{abstract}

Ao mesmo tempo em que a pesquisa não deve ser vista como uma mera preparação para projetos de intervenção, todavia, ela também não deveria ser observada e conduzida como simples aplicação de um método que, per si, viria a extrair os fatos concretos e a verdade da realidade. Os métodos são discursos - ou máquinas discursivas ${ }^{4}$ - que propõem/ produzem o estabelecimento de um conjunto de relações entre elementos da realidade de acordo com uma lógica ou um conjunto de regras/ critérios próprios. Isso significa que os métodos não são - ao contrário do que se costuma postular - mediadores neutros e universais. Mesmo os métodos aparentemente mais duros e impessoais, como os quantita-

Educação \& Realidade, Porto Alegre, v. 38, n. 4, p. 1327-1349, out./dez. 2013.1333 Disponível em: <http://www.ufrgs.br/edu_realidade> 
A Teoria do Discurso de Laclau e Mouffe e a Pesquisa em Educação

tivos, trazem em sua bagagem uma série de pressupostos tácitos sobre o que é um dado científico, que tipos de dados devem ser considerados relevantes, como se constituem as relações e processos sociais, qual o papel do pesquisador na produção do conhecimento etc. As escolhas metodológicas, portanto, baseiam-se em propostas discursivas que devem ser reconhecidas e postas em jogo no processo de pesquisa. Por outro lado, a pesquisa também não deveria ser vislumbrada como um procedimento de verificação direta ou teste de uma hipótese ou teoria. As formulações teóricas também são discursos opacos e interessados, que constituem a realidade e que, portanto, não podem representá-la de forma neutra ou imparcial. A relevância de uma teoria em um dado contexto depende de sua capacidade de interagir com esse contexto, de ser apropriada por/para ele e de produzir sentidos que possam mobilizar a realidade, não por sua suposta capacidade de reproduzir formalmente - a partir de uma pretensa exterioridade - a dinâmica fundamental da realidade $e m$ si.

A primeira tarefa de uma pesquisa fundamentada na teoria do discurso, portanto, é construir teoreticamente o problema a ser investigado - a fase de problematização ${ }^{5}$ - já a partir de uma interrogação sobre os problemas que são apresentados pelos próprios discursos sociais, no campo observado, sobre como esses problemas são construídos, quais as vias de solução intuídas nesses discursos, e sobre como essas soluções possíveis são condicionadas pelos problemas que e como são formulados. A produção de pesquisas e discussões teóricas já se constitui assim - na medida em que contribui para interpelar, articular, deslocar, legitimar e/ou contestar sentidos e lógicas que circulam no campo social - em um movimento de intervenção na realidade. Intervenção, não no sentido da proposição direta de estratégias de resolução dos problemas reconhecidos na realidade social a partir dos parâmetros - ou das regras do jogo - que configuram essa própria realidade e constituem esses problemas enquanto tais. Mas, no sentido do questionamento da naturalidade ou essencialidade dessa realidade e das regras mesmas que a constituem.

Os trabalhos de Alice Lopes (2012; 2006) oferecem uma boa perspectiva desse modo de problematização. Ao analisar as reformas educacionais da década de 1990 e o processo de adoção de um modelo de currículo nacional no Brasil, por exemplo, Lopes não se limita a buscar compreender como se caracteriza o contexto atual das políticas de currículo no país e quais os principais problemas e alternativas que se apresentam nesse contexto. Em uma perspectiva mais radical, busca investigar quais as condições discursivas que possibilitaram a emergência - e que permitem a sustentação - dessa concepção hegemônica de currículo e, ainda, como essas condições atuaram e atuam na construção e consolidação dessa hegemonia. A autora (Lopes, 2012; Lopes; Oliveira, 2011) propõe, para tanto, uma articulação entre a abordagem dos ciclos de política ${ }^{6}$ de Ball (1994) e a teoria do discurso (Laclau;

1334 Educação \& Realidade, Porto Alegre, v. 38, n. 4, p. 1327-1349, out./dez. 2013. Disponível em: <http://www.ufrgs.br/edu_realidade> 
Mouffe, 2001) para fundamentar a análise de como diferentes grupos sociais e comunidades epistêmicas - para além das agências internacionais e dos atores internos ao próprio Estado - são atravessados por e contribuem com o processo de afirmação e naturalização do modelo de currículo nacional. Mesquita (2010), ao discutir a relação entre escola pública e movimentos sociais, também desenvolve sua problematização questionando as próprias condições e discursos - republicanos, liberais, democrático-representativos - implicados na formação do sistema público de ensino no Brasil. Demonstra, então, como a atuação e articulação desses discursos passa a definir as próprias possibilidades e limites do ensino público e suas relações com os movimentos sociais no país.

Deve ser ressaltado também que, uma vez que a discursividade é considerada como uma característica intrínseca à própria realidade, e a construção da metodologia nas pesquisas referenciadas na teoria do discurso deve ser feita em função da problematização desenvolvida, as possibilidades de utilização de diferentes técnicas e recursos no desenho metodológico dessas pesquisas tornam-se - contanto que se atendam aos critérios da consistência teórica e da viabilidade prática - bastante amplas. Consequentemente, é possível identificar pesquisas inspiradas pela teoria do discurso que desenvolvem, entre outros, análise de documentos, de entrevistas, narrativas, imagens, produtos audiovisuais, dados etnográficos, mesmo dados estatísticos e, frequentemente, mais de uma dessas alternativas combinadas (Burity, 2007; Sales Jr. 2007; Mesquita, 2006).

\section{A Lógica da Explicação Retrodutiva}

Uma segunda proposição teórico-metodológica de Glynos e Howarth (2007) sugere a adoção de um modelo de racionalidade retrodutiva, em contraste aos modelos de racionalidade indutiva e dedutiva utilizados nos padrões tradicionais de explicação científica. Essa perspectiva está relacionada à crítica da noção de predição, stricto senso, nas ciências sociais, e à consequente crítica às noções de teste, confirmação ou refutação de hipóteses. Também implica, necessariamente, na flexibilização da distinção - sustentada por Popper (1980) - entre os contextos da descoberta e da justificação na pesquisa científica. O modelo hipotético-dedutivo, hegemônico na ciência contemporânea, preconiza que o avanço das ciências humanas - assim como das naturais - deve ocorrer através da formulação de hipóteses formais e verificáveis, ou falseáveis, que devem ser postas à prova através da realização de previsões precisas e testes empíricos. Nessa perspectiva, a explicação de um fenômeno implica essencialmente na formulação de uma lei ou hipótese causal que, por definição, deve ser sempre capaz de determinar as causas e prever - dedutivamente - os efeitos do fenômeno em questão. Para Popper (1980), não importa como a hipótese surgiu ou foi formulada - o chamado contexto da descoberta - essa é uma questão que diria

Educação \& Realidade, Porto Alegre, v. 38, n. 4, p. 1327-1349, out./dez. 2013.1335 Disponível em: <http://www.ufrgs.br/edu_realidade> 
A Teoria do Discurso de Laclau e Mouffe e a Pesquisa em Educação

respeito somente aos psicólogos cognitivos, interessados nos processos de formação e elaboração de ideias. O que preme ao epistemólogo, ou ao filósofo da ciência, é estabelecer como tal hipótese pode e deve ser testada - ou o contexto da justificação - o que visa determinar até que ponto a mesma merece ou não ser aceita como científica e/ou ser sustentada como válida.

A crítica à utilização das noções de lei causal e predição na explicação dos fenômenos sociais já vem sendo longamente desenvolvida pelas tradições fenomenológica e hermenêutica nas ciências humanas e na educação ${ }^{7}$. A perspectiva hermenêutica indica, corretamente, que o comportamento humano é intrinsecamente constituído por práticas significantes, as quais estão diretamente relacionadas aos sentidos atribuídos a cada ação ou elemento da realidade pelos jogos de linguagem dos quais cada sujeito - inclusive o pesquisador - participam. Seria impraticável, portanto, determinar relações lineares de causa e efeito e/ou realizar previsões precisas e inexoráveis sobre o comportamento humano ou social, uma vez que os processos de interpretação e construção de sentidos seriam abertos e, ao menos em certa medida, indeterminados. Além do que, como ressaltado, as próprias interpretações oferecidas pelos discursos científicos também participam desse jogo, são atravessadas por e interferem - direta ou indiretamente - nos fenômenos que se propõem a estudar. Nesse contexto, para alguns, só caberia aos pesquisadores e cientistas propor interpretações específicas e localizadas dos fenômenos estudados, nunca buscar explicações que venham a exceder a dimensão do significado atribuído pelos sujeitos às suas próprias ações ou, no máximo, a tradução desse significado para uma linguagem acadêmica ou mais universalizada. A racionalidade retrodutiva pode ser apresentada, entretanto, como uma alternativa viável para produzir e validar explicações nas ciências humanas e sociais, partindo das significações construídas pelos sujeitos, mas, sem limitarse exclusivamente a interpretar essas significações em seus contextos.

A retrodução consiste em uma dinâmica de formulação de relações em que o processo de construção de enunciados não parte de certas condições antecedentes para concluir suas consequências, como na dedução, nem parte de eventos específicos para enunciar uma regra, como na indução. Na lógica retrodutiva, o analista busca enunciar as condições que seriam necessárias para, ou que tornariam possível a ocorrência de determinado fenômeno ${ }^{8}$. A explicação de um fato investigado, assim, não implica em estabelecer uma lei causal, em demonstrar uma necessidade lógica absoluta ou em predizer que, dadas as mesmas condições, o fenômeno se repetirá obrigatoriamente. Implica simplesmente em afirmar que, para que a realidade observada seja constituída tal como ela se apresenta, certas condições foram e são necessárias. É importante destacar que pode haver diversos cenários que tornem viável uma mesma realidade, e que as condições de possibilidade indicadas podem ser necessárias, mas, não suficientes per si para produzir o

1336 Educação \& Realidade, Porto Alegre, v. 38, n. 4, p. 1327-1349, out./dez. 2013 Disponível em: <http://www.ufrgs.br/edu_realidade> 
fenômeno estudado. A enunciação das condições necessárias para que uma dada forma de organização simbólica e social da realidade seja possível, por exemplo, ultrapassa - embora tenha sempre de partir desse ponto - a simples autointerpretação que os sujeitos articulam sobre suas ações e seu contexto. A explicação oferecida por essa enunciação, entretanto, não permite sua formulação como uma lei causal ou generalizada, uma vez que ela não se inclina a fornecer predições ou padrões de regularidade que possam ser testados, nem busca forjar um modelo positivo e totalizado da realidade social.

A construção de hipóteses nas ciências humanas e sociais já segue, em geral, o processo de busca das explicações aparentemente mais plausíveis-ou que descrevem as condições mais prováveis - para a ocorrência do fenômeno investigado. Na perspectiva hipotético-dedutiva, o passo seguinte seria reduzir a hipótese defendida a variáveis formais e indicadores - preferencialmente quantitativos - os quais deveriam permitir a realização de testes empíricos para determinar a validade ou falsidade das correlações propostas. É imprescindível questionar, nesse caso, até que ponto todos os elementos presentes em um campo social são redutíveis a indicadores formais e quantificáveis e, quando realizada, até que ponto a tradução de uma situação social complexa em variáveis e indicadores formais pode permanecer significativa em relação ao contexto de estudo. É necessário, também, chamar a atenção para o fato de que as próprias operações de redução e tradução não são - e não podem ser - efetivamente neutras, como se pretendem, mas, são atravessas pelas crenças, posições subjetivas e opções éticas e políticas dos pesquisadores, que permanecem veladas sob o manto ideológico da objetividade e neutralidade científica. Uma pesquisa orientada pela teoria do discurso é virtualmente incompatível com o modelo hipotético-dedutivo, conforme apresentado, e demanda a articulação de um modelo de explicação que reconheça o caráter precário, contingente e intrinsecamente comprometido do próprio discurso científico.

A alternativa defendida é a utilização da racionalidade retrodutiva não somente para a construção das hipóteses, mas, também para a validação das explicações nas ciências sociais. Em lugar de passar da construção de hipóteses para a derivação de testes empíricos, a lógica da pesquisa passa a seguir em sucessivos ciclos retrodutivos, (re)elaborando consecutivamente a hipótese delineada de acordo com a ampliação ou aprofundamento do conhecimento construído sobre o campo analisado. Esse modelo já é utilizado na prática - muitas vezes de forma intuitiva, confusa ou mesmo contraditória - por grande parte das pesquisas que se propõem adotar uma abordagem qualitativa de investigação. A validação ou aceitação do conhecimento produzido, nessa perspectiva, não depende da obtenção de provas ou de sua resistência ao falseamento. Depende, em última instância, de fatores relacionados à sua capacidade de convencimento da comunidade científica e dos atores sociais e, sobretudo, de seu poder de articulação e/ou de contestação crítica em relação à problemática e aos fenômenos investigados.

Educação \& Realidade, Porto Alegre, v. 38, n. 4, p. 1327-1349, out./dez. 2013. 1337 Disponível em: <http://www.ufrgs.br/edu_realidade> 
A Teoria do Discurso de Laclau e Mouffe e a Pesquisa em Educação

Os contextos da descoberta e da justificação encontram-se, nesse caso, parcialmente sobrepostos (Figura 1). A pesquisa é vista como uma atividade social que compreende os dois processos, como um todo, e os mecanismos de justificação não podem ser utilizados como fetiches para projetar a teoria acima do campo agonístico dos conflitos sociais e políticos.

Figura 1 - Dois Retratos das Ciências Sociais

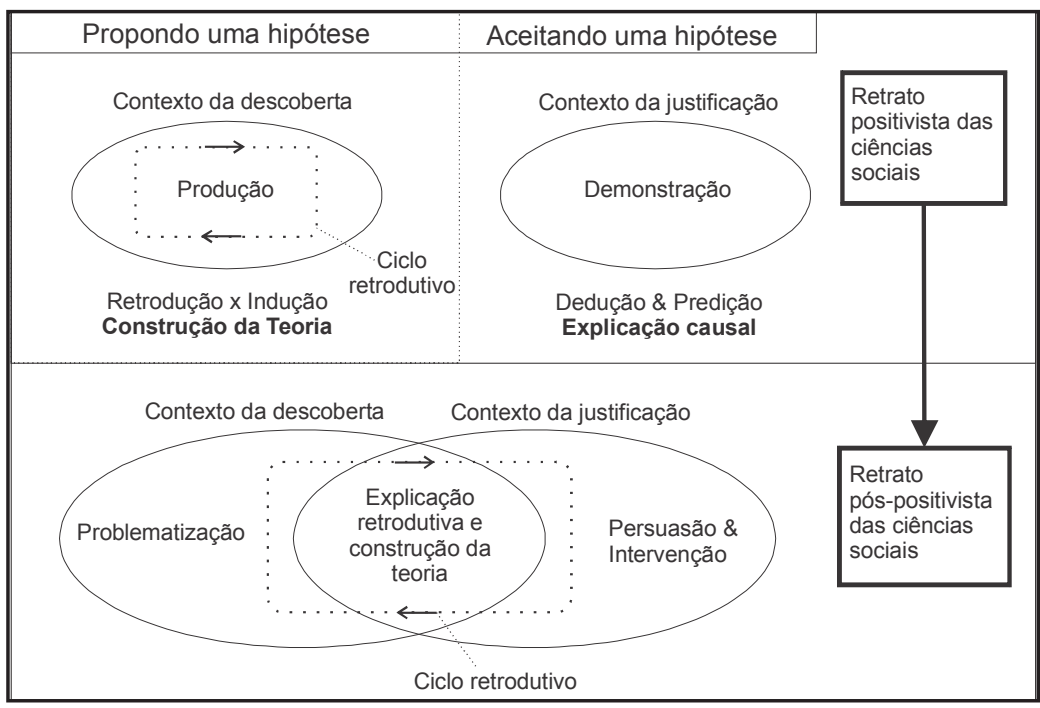

Fonte: (Glynos; Howarth, 2007, p. 33).

Além dos trabalhos de Alice Lopes e Rui Mesquita, citados anteriormente, dois outros estudos que podem ser examinados para exemplificar a utilização - explícita ou não - da lógica retrodutiva são os trabalhos de Elizabeth Macedo (2006) e Anna Luiza Oliveira (2011). Macedo (2006) propõe uma discussão sobre como a questão da cultura - especialmente da diferença ou da diversidade cultural - é articulada nos textos dos Parâmetros Curriculares Nacionais (PCN) do ensino fundamental. A análise também assume uma leitura do ciclo contínuo de políticas de Stephen Ball ${ }^{9}$ inspirada pela teoria do discurso. Reconhece que os textos dos PCN não são “[...] o guia absoluto da prática curricular” (Macedo, 2006, p. 163) nem, tampouco, são simplesmente o "[...] produto da mente de seus formuladores" (Macedo, 2006, p. 163). Os Parâmetros são apresentados, desse modo, como um produto cultural, construído através dos embates e negociações entre diferentes posições, nos diferentes contextos de circulação das políticas de currículo. A partir da análise dos textos dos PCN, portanto, a autora busca investigar quais os principais discursos que se articularam na construção da concepção de cultura - ou de diversidade cultural - que se torna dominante nos PCN, como essa articulação se tornou possível e quais as perspectivas - de hibridização e de diferença - negadas ou excluí-

1338 Educação \& Realidade, Porto Alegre, v. 38, n. 4, p. 1327-1349, out./dez. 2013. Disponível em: <http://www.ufrgs.br/edu_realidade> 
das pelo discurso estabelecido. É interessante perceber que análise em questão não busca testar uma hipótese nem estabelecer uma relação causal regular entre elementos. Por outro lado, ela também não se detém somente na interpretação das noções de cultura e diversidade cultural enunciadas pelos PCN. Ela parte de uma realidade observada para buscar reconhecer - de forma cada vez mais nuançada - as condições que possibilitaram a construção dessa realidade e, consequentemente, para desafiar a naturalização da mesma. O estudo de Anna Luiza Oliveira (2011) segue uma dinâmica semelhante à observada no trabalho de Macêdo (2006). Contudo, a autora trabalha mais especificamente com a temática da diversidade sexual, propõe uma articulação entre a teoria do discurso e a teoria queer (Oliveira et al., 2013) e desenvolve sua análise a partir de entrevistas com professores/as e gestores/as de escolas públicas que entraram em contato com materiais e/ou cursos de formação sobre educação e diversidade sexual. A análise, nesse caso, permite a autora demonstrar como os discursos sobre a diversidade enunciados e vivenciados na prática cotidiana por docentes e gestoras/ es são construídos através de negociações e articulações entre os discursos emitidos pelo MEC e pelas agências de formação, e os diferentes discursos religiosos, familiares, midiáticos e sociais sobre o tema que permanecem em circulação nos espaços escolares.

\section{As Lógicas como Unidades Explicativas}

A terceira proposição analisada, em relação às pesquisas identificadas com a teoria do discurso, refere-se à adoção do conceito de lógica como unidade explicativa básica na teorização dos fenômenos observados no campo social. A racionalidade retrodutiva provê um modelo eficiente para a construção de explicações, todavia, uma questão que permanece em aberto diz respeito a qual o tipo de explicação que pode ser obtido quando se estuda tais fenômenos. Já foi discutido, recuperando os argumentos da tradição hermenêutica, que a unidade explicativa proposta pelo positivismo clássico - a lei causal, natural e/ ou universal - se mostra claramente incoerente com a percepção dos sujeitos humanos como distintivamente discursivos, sempre já constituídos e atravessados por um universo significante, os quais agem e se definem de acordo com redes ou jogos de sentido que ordenam a realidade. A tradição hermenêutica, entretanto, também não oferece uma alternativa suficientemente satisfatória ao conceito de lei - ou ainda de hipótese - causal.

A unidade explicativa - ou de compreensão - dos fenômenos sociais na perspectiva hermenêutica, em geral, poderia ser definida como a autointerpretação contextual dos sujeitos. Cada sujeito ou grupo social constrói, de forma intersubjetiva, sua própria interpretação do mundo. Os elementos fundamentais - e limites - para a explicação ou compreensão das ações de cada sujeito seriam, portanto, as interpretações que ele desenvolve sobre si mesmo e sobre sua realidade. O primeiro pro-

Educação \& Realidade, Porto Alegre, v. 38, n. 4, p. 1327-1349, out./dez. 2013. 
A Teoria do Discurso de Laclau e Mouffe e a Pesquisa em Educação

blema com essa perspectiva, em linhas simples, é que ela não permite analisar como esse sistema de sentidos foi ou é constituído e quais as suas contradições e/ou possibilidades de transformação. Consequentemente, a abordagem puramente hermenêutica também não proporciona, por si mesma, ferramentas para o desenvolvimento de análises relacionais e comparativas entre diferentes contextos, nem para uma crítica desconstrutiva - que não seja enunciada a partir de uma racionalidade totalmente alheia ao próprio campo - e que permita deslocar e dinamizar os sentidos fixados nos discursos sociais.

Autores que trabalham na perspectiva do realismo crítico, como Roy Bhaskar (1989) e Margaret Archer (1979) ${ }^{10}$, propõem a adoção do conceito de mecanismos causais como alternativa tanto às leis gerais do positivismo quanto às interpretações contextuais e descritivas da tradição hermenêutica. Os mecanismos causais, de modo geral, representariam padrões de encadeamento entre ações, eventos e fenômenos no campo social que, embora ultrapassem a dimensão dos contextos interpretativos locais, não produziriam diretamente previsões verificáveis e generalizáveis. A impossibilidade da predição precisa e da construção de modelos teóricos gerais decorreria da multiplicidade e complexidade quase infinita dos mecanismos envolvidos nos processos sociais. Embora seja possível conhecer alguns mecanismos em atuação, torna-se muito difícil - senão virtualmente impossível - identificar todos os mecanismos que estão desempenhando um papel em determinado contexto e, mais ainda, determinar qual a resultante final das interações que podem se estabelecer entre todos eles. É válido destacar, entretanto, que a previsibilidade e a generalidade continuam a ser consideradas como ideais, e que a busca do maior grau possível de ambas permanece como orientação, meta e, consequentemente, como um indicador mesmo que parcial - de sucesso da pesquisa e da teorização.

A dificuldade encontrada com a proposta do realismo crítico, portanto, é que ela não leva às últimas consequências a dimensão da negatividade na constituição da realidade social ${ }^{11}$. O caráter de contingência e incompletude insuperável na construção discursiva da realidade chega a ser reconhecido no nível da epistemologia, indicando a impossibilidade de um conhecimento pleno, mas, permanece a afirmação - de forma idealizada - de uma relação de exterioridade entre um conhecimento contingente e uma realidade ontologicamente positiva. O não reconhecimento da constituição discursiva e política da própria ontologia compromete a percepção do caráter hegemônico da ciência e especialmente das ciências humanas - e reconduz um ideal de representação que interfere diretamente na compreensão do papel da pesquisa e de sua relação com a realidade social na qual se insere.

Glynos e Howarth (2007) propõem a designação da categoria de lógica - em suas dimensões sociais, políticas e fantasmáticas - como uma unidade explicativa mais promissora para a construção de modelos teóricos nas ciências sociais. As lógicas são também apresentadas

1340 Educação \& Realidade, Porto Alegre, v. 38, n. 4, p. 1327-1349, out./dez. 2013. Disponível em: <http://www.ufrgs.br/edu_realidade> 
como uma alternativa às noções de lei ou hipótese causal e de autointerpretação contextual, ou seja, como forma de superação do determinismo generalista do positivismo e do particularismo predominantemente descritivo da escola hermenêutica. Em contraste com os mecanismos causais do realismo crítico, todavia, as lógicas são reconhecidas como sempre dependentes das construções discursivas e hegemônicas dos próprios sujeitos sociais, não como realidades - ou representações de realidades - externas ao campo discursivo e hegemônico. Essa perspectiva não implica que as lógicas não participem do campo da realidade, mas, ao contrário, reconhece que a própria realidade é constituída de forma inescapavelmente discursiva.

As lógicas se caracterizam enquanto o que Laclau (2003) define como abstrações reais. Podem ser compreendidas como sistemas de regras, ou como gramáticas, que estabelecem o tipo de relações possíveis entre os elementos em um dado contexto social, as chamadas lógicas sociais. Ao mesmo tempo, as lógicas também podem definir o conjunto de condições que torna possível - e/ou vulnerável - a emergência e a sustentação - lógicas políticas e fantasmáticas - de tais sistemas. A noção de lógicas sociais, assim, é bastante próxima da noção de formação discursiva em Foucault (2000), com a importante diferença de que as lógicas sociais podem ser vistas como vigentes em contextos sociais parciais, hegemonicamente contestados e, portanto, nunca plenamente totalizáveis. Nesse sentido, as lógicas sociais estão intrinsecamente relacionadas à própria percepção da discursividade da realidade social. As lógicas políticas, por sua vez, consistem nas lógicas da equivalência e da diferença, que se relacionam com os eixos paradigmático e sintagmático na linguística estruturalista e que, para Laclau e Mouffe (2001), constituem-se nos mecanismos fundamentais de construção e contestação de articulações entre significantes, de discursos e, consequentemente, de lógicas sociais.

A noção de lógicas fantasmáticas, ou lógicas da fantasia, vem sendo proposta por Jason Glynos (Glynos, 2001; Glynos; Howarth, 2007) a partir das contribuições de Zizek (2008; 2000), fundamentadas na psicanálise lacaniana, à teoria do discurso. A noção busca suprir uma lacuna na teorização de Laclau e Mouffe (2001) em relação ao tipo de força que impulsiona a constituição, fixação e/ou ruptura das relações de articulação, identificação e oposição na formação de discursos e identidades. Para os autores, a teoria lacaniana da fantasia poderia oferecer uma resposta satisfatória a esse dilema ao relacionar os processos de identificação à necessidade de se promover uma sutura - mesmo que sempre parcial e contingente - na falta constitutiva que caracteriza o próprio sujeito. As lógicas fantasmáticas, portanto, em suas dimensões beatífica e terrífica, poderiam explicar a força que impele os sujeitos - individuais e coletivos - a sustentar os atuais e/ou a buscar novos objetos/pontos de identificação, fortalecendo/atualizando os discursos vigentes e/ou produzindo novos discursos e identidades.

Educação \& Realidade, Porto Alegre, v. 38, n. 4, p. 1327-1349, out./dez. 2013. 
A Teoria do Discurso de Laclau e Mouffe e a Pesquisa em Educação

Na perspectiva de Glynos e Howarth (2007), portanto, as pesquisas empíricas referenciadas na teoria do discurso poderiam buscar, através de uma dinâmica retrodutiva, evidenciar e enunciar as lógicas sociais, políticas e/ou fantasmáticas que constituem e contestam continuamente as realidades pesquisadas e analisadas. Em pesquisas sobre as identidades e discursos pedagógicos, políticos, raciais, sexistas ou religiosos em espaços educacionais, como os citados, para além de buscar simplesmente compreender contextualmente as realidades observadas ou, por outro lado, de buscar leis e/ou mecanismos naturais que expliquem essencialmente esses fenômenos, torna-se possível investigar quais as lógicas que constituem/contestam tais discursos em cada cenário e que, portanto, podem possibilitar a construção de explicações, embora contingentes e parciais, em relação aos processos que os envolvem. Gustavo Gilson Oliveira (2009), por exemplo, ao desenvolver uma pesquisa sobre as transformações das identidades cristãs a partir da pluralização do campo religioso brasileiro, evidenciou, dentre outros aspectos, como a crise das metanarrativas modernas e o advento da mídia de massa no Brasil - para além do seu próprio crescimento numérico - foram fatores primordiais para o deslocamento das identidades religiosas pentecostais de uma posição de negação e marginalidade em relação à sociedade moderna, para a construção de uma forte articulação - sobretudo através do neopentecostalismo - com algumas das lógicas centrais do capitalismo e da cultura contemporânea. O deslocamento observado - que se desenvolveu através da constituição de novas posições de identificação e diferenciação - implicou diretamente na formação de novas lógicas sociais religiosas e, do mesmo modo, foi mobilizado intimamente pelo surgimento de novas fantasias sociais em relação às imagens de paraíso e de inferno projetadas. Esse movimento torna-se extremamente relevante para os debates atuais nos campos da educação e do currículo (Oliveira, 2012), na medida em que a emergência dessas novas identidades, discursos e lógicas religiosas no espaço público passam a também a desafiar - juntamente com outros fenômenos - as próprias concepções modernas e hegemônicas de educação e escolarização como formação cultural secularizada e universalizada.

\section{A Articulação como Modelo de Relação entre Teoria e Realidade}

A quarta proposição teórico-metodológica analisada, a partir da formulação de Glynos e Howarth (2007), está relacionada simultaneamente à dimensão crítica do trabalho científico e ao processo de validação, justificação ou aceitação de uma hipótese ou modelo teórico. Diz respeito à rejeição da noção dualista de aplicação ou emprego instrumental de uma metodologia, teoria, conceito ou princípio geral - o que Glynos e Howarth chamam de problema da subsunção - em favor da perspectiva da articulação como modelo de relação - sempre ativa e mutuamente implicada - entre as formulações teóricas e a realidade

1342 Educação \& Realidade, Porto Alegre, v. 38, n. 4, p. 1327-1349, out./dez. 2013. Disponível em: <http://www.ufrgs.br/edu_realidade> 
social. Uma vez que não há como traçar uma relação de exterioridade rígida entre o campo discursivo social e os discursos teóricos ou científicos, a construção dos modelos teóricos ou abstratos só pode ser efetuada através da proposição de articulações - ou conexões simbólicas e reais - entre os conceitos e categorias enunciados a partir das elaborações teóricas, e entre esses e os já presentes nos discursos sociais. Deve-se destacar que o potencial para a construção de articulações não é uma prerrogativa dos intelectuais ou analistas científicos, essas articulações são construídas, desafiadas e deslocadas continuamente por processos hegemônicos dos quais o discurso científico participa como apenas um dentre vários enunciadores possíveis. Do mesmo modo, as articulações encetadas pelo discurso científico não podem ser vistas como neutras, indiferentes ou meramente intelectuais, pois produzem efeitos - quer diretos ou indiretos, em maior ou menor medida - na própria constituição da realidade analisada.

Contra a tendência naturalista a subsumir, nós favorecemos uma abordagem baseada na intuição, na capacidade teorética e na prática da articulação. Isso significa que, tendo imergido a si mesmo em um dado campo discursivo formado por textos, documentos, entrevistas e práticas sociais, o pesquisador ou pesquisadora trabalha sobre sua capacidade teorética para fazer julgamentos específicos sobre até que ponto algo conta como um " $x$ ", e deve então decidir sobre sua importação global para o problema investigado. [...] Parte integral de julgar até que ponto um fenômeno empírico particular conta como um exemplo de "x" consiste em decidir qual é precisamente a relevância e a importância que " $x$ " representa para a construção de uma narrativa que explique o fenômeno. [...] Julgamento, então, é um tipo de habilidade situada na qual um sujeito - um sujeito pesquisador no nosso caso específico - adquire e desempenha a capacidade de conectar um conceito a um objeto, ou de "aplicar" uma lógica a uma série de processos sociais, no interior de um quadro teórico contingente e contestável (Glynos; Howarth, 2007, p. 184).

A validade ou o valor de um trabalho científico, nesse contexto, não podem ser coerentemente avaliados de acordo com o suposto grau de fidelidade ou precisão com o qual ele retrata ou reproduz a dinâmica natural da realidade social. Não há uma realidade externa ao campo discursivo - no sentido de que o que seja externo ao campo discursivo está para além da realidade - nem um discurso científico radicalmente externo ao campo social e, portanto, o que estabelece o valor de uma teorização científica é sua capacidade de (des)articular de forma o mais consistente e convincente possível - para a comunidade científica e para os próprios atores sociais - os elementos da realidade analisada, cumprindo o papel de crítica e/ou de sustentação de posições ou discursos que se apresentam no campo hegemônico do social. A justificação das explicações e formulações teoréticas propostas pela pes-

Educação \& Realidade, Porto Alegre, v. 38, n. 4, p. 1327-1349, out./dez. 2013. 
A Teoria do Discurso de Laclau e Mouffe e a Pesquisa em Educação

quisa, nesse caso, não deixa de estar condicionada por fatores como a seriedade e confiabilidade das informações produzidas, a honestidade intelectual e o compromisso acadêmico das pesquisadoras/es ou a coerência, profundidade e alcance das teses, interpretações e argumentos apresentados. Todavia, todos esses fatores são articulados como alguns vetores - dentre diversos possíveis - que potencializam a capacidade de convencimento desses discursos científicos e, ainda mais, vetores cujas próprias definições e sentidos específicos dependem das concepções de conhecimento e ciência dominantes em cada contexto.

É importante retomar, nesse ponto, a discussão sobre a questão do rigor analítico e sobre o potencial crítico da teoria do discurso e das perspectivas pós-estruturalistas, especialmente na educação. Uma das queixas mais comuns quanto ao papel e ao potencial das abordagens pós-estruturalistas nas pesquisas em educação ${ }^{12}$ diz respeito aos seus supostos irracionalismo e subjetivismo e à sua recusa da possibilidade de construção de um conhecimento científico pretensamente objetivo e universal. A ideia disseminada é de que o pós-modernismo, como signo representante de todas as perspectivas pós, ao desconstruir as narrativas modernas de progresso, emancipação humana e avanço da razão universal, eliminou qualquer possibilidade de racionalidade e de afirmação de um conhecimento válido para além dos limites das paixões, opiniões e interesses de cada sujeito ou grupo social. A partir das concepções apresentadas e analisadas neste artigo, entretanto, tornase possível questionar solidamente essa percepção. Em primeiro lugar deve-se destacar que, embora haja realmente temas e características em comum entre a maioria dos autores/as e teorias comumente classificadas como pós-modernas ou pós-estruturalistas, essas abordagens são bastante numerosas e extremamente diversas entre si, apresentando níveis de complexidade, inclinações políticas, nuanças e divergências que não são facilmente planificadas e adaptadas em uma descrição sintética e simples. Desprezar essas diferenças e os processos lógicos de cada perspectiva é recair em uma crítica superficial e estereotipada, abandonando o próprio debate racional que se busca defender.

O segundo questionamento que pode ser feito em relação à crítica apresentada anteriormente se refere propriamente às acusações de irracionalismo e subjetivismo. Sem dúvida, as teorias reconhecidas como pós-modernas e pós-estruturalistas tem como uma de suas principais características a negação radical do projeto ocidental e moderno de racionalidade universal, com suas diversas facetas sociais e políticas. Essa negação, contudo, não implica necessariamente num abandono absoluto da razão, nem mesmo numa rejeição a qualquer possibilidade ou modelo de racionalidade ou de proposta de mundo. Afirmar que todo projeto de racionalidade é constituído a partir de lógicas parciais e contingentes, atravessadas por relações de poder, não significa negar a possibilidade de qualquer racionalidade ou mesmo negar sua importância como fator de articulação de sentidos e de uma realidade

1344 Educação \& Realidade, Porto Alegre, v. 38, n. 4, p. 1327-1349, out./dez. 2013. Disponível em: <http://www.ufrgs.br/edu_realidade> 
comum. Ao contrário, significa indicar que qualquer realidade humana somente torna-se possível através da construção de discursos que articulam sentidos e lógicas racionais em seu contexto. Significa também, todavia, reconhecer que não existe uma racionalidade única ou natural, independente das convenções, regras ou lógicas estabelecidas em cada contexto e, portanto, que todo o projeto de universalidade - inclusive o da racionalidade ocidental - é sempre já um projeto comprometido e precário, passível de resistência, deslocamento e contestação por outras lógicas e discursos.

Essa perspectiva também não vem a implicar que os discursos ou projetos racionais sejam elementos que se só possam ser construídos ou julgados a partir das subjetividades e interesses individuais ou particulares, ou que não possa haver critérios e padrões comuns para avaliar diferentes afirmações e propostas. Na teoria do discurso, em especial, os processos de constituição, reprodução e contestação de discursos e racionalidades são sempre processos de disputa hegemônica, desempenhados por sujeitos coletivos contingentes, forjados a partir de movimentos de identificação e diferenciação simbólica. Os critérios para julgar afirmações e propostas divergentes ou conflitantes, portanto, são também constituídos e disputados hegemonicamente, não estabelecidos desde uma lógica natural ou universal. No campo acadêmico, desse modo, existem e precisam existir, por definição, critérios e padrões para avaliar e avalizar as interpretações e discursos teóricos produzidos em nome da ciência. Esses mesmos critérios e padrões, porém, também não são absolutos e isentos das construções e disputas hegemônicas. Estão e precisam estar, por conseguinte, continuamente abertos e passíveis de crítica, contestação e justificação. Como se pode observar a partir do debate realizado, as abordagens pós-estruturalistas e a teoria do discurso, particularmente, não prescindem e não diluem a necessidade do aprofundamento, do rigor analítico, da racionalidade ou da objetividade - no sentido de reconhecimento da implicação objetiva - na realização de pesquisas e teorizações em educação ou ciências humanas. Pelo contrário, essas perspectivas radicalizam a exigência de rigor analítico e da verve crítica ao levar às últimas consequências as implicações da crítica racional sobre seus próprios fundamentos e justificativas.

Recebido em 06 de junho de 2012 Aprovado em 24 de maio de 2013

\section{Notas}

1 É necessário indicar que essas denominações são consideravelmente imprecisas e conflitivas, uma vez que nem todas as abordagens pós-estruturalistas são necessariamente defensoras do pós-modernismo, por exemplo, e que muitas mantém um viés crítico radical.

2 Podem ser destacadas as análises de Foucault sobre a sexualidade, as instituições penais e as tecnologias de governo como a medicina e a psiquiatria; os estudos de Lacan sobre os distúrbios psíquicos, a família ou a arte; as análises de Deleuze e Guattari sobre o capitalismo e as instituições psiquiátricas; os

Educação \& Realidade, Porto Alegre, v. 38, n. 4, p. 1327-1349, out./dez. 2013. 
A Teoria do Discurso de Laclau e Mouffe e a Pesquisa em Educação

trabalhos de Derrida sobre religião, tecnologia e políticas de identidade; entre outros.

3 Alguns trabalhos que articulam explicitamente essa preocupação são: Burity (2007), Sales Júnior (2007), Torfing (2005), Howarth (2005 e 2000), Howarth e Stavrakakis (2000) e Norval (2000).

4 A metáfora da máquina discursiva é utilizada recorrentemente por Derrida (2000) para caracterizar o conjunto de engrenagens lógicas que constituem, ao mesmo tempo, a estrutura e a dinâmica produtiva de um discurso.

5 O conceito de problematização é desenvolvido por Foucault (1984) para indicar o procedimento de busca pelas condições de possibilidade que viabilizam a constituição de um dado problema como tal.

6 A abordagem do ciclo contínuo de políticas de Stephen Ball questiona o modelo tradicional de compreensão das políticas de educação como políticas que emanam do estado para a sociedade civil. Ball (1996) defende que os processos de formulação e atualização das políticas de educação se desenvolvem através de um ciclo contínuo de (re)elaboração que atravessa diferentes contextos. Os três principais contextos indicados por Ball são: i) O contexto da influência; ii) O contexto da produção de textos; iii) o contexto da prática.

7 Por exemplo, os trabalhos de Boaventura Santos (1997; 1989).

8 Para uma apresentação mais ampla e detalhada sobre conceito de retrodução - ou abdução - ver Peirce (1983) e Hanson (1961).

9 Ver a nota anterior sobre a abordagem do ciclo de políticas de Ball.

10 Para uma discussão geral sobre a perspectiva do realismo crítico na educação ver Shipway (2011)

11 Esse debate pode ser observado diretamente em Laclau e Bhaskar (1998).

12 Por exemplo Moraes (2009, 2001) e Dentz (2011).

\section{Referências}

ALVES-MAZZOTTI, Alda Judith. Relevância e Aplicabilidade da Pesquisa em Educação. Cadernos de Pesquisa, São Paulo, n. 113, p. 39-50, jul. 2001.

ANDRÉ, Marli. Pesquisa em Educação: buscando rigor e qualidade. Cadernos de Pesquisa, São Paulo, n. 113, p. 51-64, jul. 2001.

ARCHER, Margaret. Social Origins of Educational Systems. London: Sage, 1979. BACKES, José Licínio; PAVAN, Ruth. As Epistemologias dos Estudos Curriculares: diferenças e identidades. Educação e Realidade, Porto Alegre, v. 36, n. 2, p. 465-483, maio/ago. 2011.

BALL, Stephen. Education Reform: a critical and post-structural approach. Buckingham: Open University, 1994.

BHASKAR, Roy. Reclaiming Reality. London: Verso, 1989.

BURITY, Joanildo. Teoria do Discurso e Educação: reconstruindo o vínculo entre cultura e política. Revista Teias, Rio de Janeiro, n. 11, v. 22, p. 7-29, 2010.

BURITY, Joanildo. Teoria do Discurso e Análise do Discurso: sobre política e método. In: WEBER, Silke; LEITHAUSER, Thomas (Org.). Métodos Qualitativos nas Ciências Sociais e na Prática Social. Recife: Editora da UFPE, 2007.

COSTA, Marisa Vorraber (Org.). Caminhos Investigativos I: novos olhares na pesquisa em educação. Rio de Janeiro: Lamparina Editora, 2007.

COSTA, Marisa Vorraber (Org.). Caminhos Investigativos II: outros modos de pensar e fazer pesquisa em educação. Rio de Janeiro: DP\&A, 2002.

1346 Educação \& Realidade, Porto Alegre, v. 38, n. 4, p. 1327-1349, out./dez. 2013.

Disponível em: <http://www.ufrgs.br/edu_realidade> 
COSTA, Marisa Vorraber; BUJES, Maria Isabel. Caminhos Investigativos III: riscos e possibilidades de pesquisar nas fronteiras. Rio de Janeiro: DP\&A, 2005. CUNHA, Luiz Antônio. Pós-Graduação em Educação: ponto de inflexão? Cadernos de Pesquisa, São Paulo, n. 77, p. 63-80, maio 1991.

DENTZ, Volmir Von. Elementos Para uma Crítica Ontológica ao Relativismo Epistemológico nas “Teorias” Pós-Críticas em Educação. Atos de Pesquisa em Educação, Blumenau, v. 6, n. 2, p. 356-372, maio/ago. 2011.

DERRIDA, Jacques. Fé e Saber: as duas fontes da religião nos limites da simples razão. In: DERRIDA, Jacques; VATTIMO, Gianni. A Religião. São Paulo: Estação Liberdade, 2000. P. 11-89.

FOUCAULT, Michel. As Palavras e as Coisas: uma arqueologia das ciências humanas. São Paulo: Martins Fontes, 2000.

FOUCAULT, Michel. História da Sexualidade 2: o uso dos prazeres. Rio de Janeiro: Graal, 1984

GATTI, Bernadete. Implicações e Perspectivas da Pesquisa Educacional no Brasil contemporâneo. Cadernos de Pesquisa, São Paulo, n. 113, p. 65-81, jul. 2001.

GATTI, Bernadete. Algumas Considerações Sobre Procedimentos Metodológicos nas Pesquisas Educacionais. ECCOS - Revista Científica, São Paulo, v.1, n. 1, dez. 1999.

GLYNOS, Jason. The Grip of Ideology: a Lacanian approach to the theory of ideology. Journal of Political Ideologies, London, v. 6, n. 2, p. 191-214, 2001.

GLYNOS, Jason; HOWARTH, David. Logics of Critical Explanation in Social and Political Theory. London/New York: Routledge, 2007.

HANSON, Norwood. Patterns of Discovery. Cambridge: Cambridge University Press, 1961.

HOWARTH, David. Applying discourse theory: the method of articulation. In: TORFING, Jacob; HOWARTH, David. Identity, Policy and Governance. New York: Palgrave, 2005.

HOWARTH, David. Discourse. Buckingham: Open University Press, 2000.

HOWARTH, David; STAVRAKAKIS, Yannis. Introducing discourse theory and political analysis. In: HOWARTH, David; NORVAL, Aletta; STAVRAKAKIS, Yannis (Org.). Discourse theory and Political Analysis: Identities, hegemonies and social change. Manchester/New York: Manchester University, 2000.

LACLAU, Ernesto. On Populist Reason. London: Verso, 2005.

LACLAU, Ernesto. Identidad y hegemonía: el rol de la universalidad en la constituición de lógicas políticas. In: BUTLER, Judith; LACLAU, Ernesto; ZIZEK, Slavoj. Contingencia, Hegemonía, Universalidad: Diálogos contemporáneos en la izquierda. Buenos Aires: Fondo de Cultura Económica, 2003.

LACLAU, Ernesto; BHASKAR, Roy. Discourse Theory vs. Critical Realism. Journal of Critical Realism - Alethia, London, v. 1, n. 2, p. 9-14, 1998.

LACLAU, Ernesto; MOUFFE, Chantal. Hegemony and Socialist Strategy: Toward a Radical Democratic Politics. London: Verso, 2001.

LACLAU, Ernesto; MOUFFE, Chantal. Posmarxismo sin pedido de disculpas. In: LACLAU, Ernesto. Nuevas Reflexiones Sobre la Revolución de Nuestro Tiempo. Buenos Aires: Nueva Visión, 2000.

LOPES, Alice. Políticas de currículo: questões teórico-metodológicas. In: LOPES, Alice et al. Discursos nas Políticas de Currículo. Rio de Janeiro: Quartet, 2012.

LOPES, Alice. Discursos nas políticas de currículo. Currículo sem Fronteiras, v.6, n.2, p.33-52, 2006.

Educação \& Realidade, Porto Alegre, v. 38, n. 4, p. 1327-1349, out./dez. 2013. 
A Teoria do Discurso de Laclau e Mouffe e a Pesquisa em Educação

LOPES, Alice; MACEDO, Elizabeth. Teorias de Currículo. São Paulo: Cortez, 2011.

LOPES, Alice; OLIVEIRA, Ana. A abordagem do ciclo de políticas: uma abordagem pela teoria do discurso. Cadernos de Educação, v. 38, p. 19-41, 2011.

MACEDO, Elizabeth. A diferença nos PCN do ensino fundamental. In: LOPES, Alice; MACEDO, Elizabeth. Políticas de Currículo em Múltiplos Contextos. São Paulo: Cortez, 2006.

MADILL, Anna. Objectivity and reliability in qualitative analysis: Realist, contextualist and radical constructionist epistemologies. British Journal of Psychology, Leicester, v. 91, n. 1, p. 1-20, feb. 2000.

MESQUITA, Rui. Movimentos sociais e escola pública: uma metodologia para analisar projetos político-pedagógicos antagonísticos. Educação e Realidade, v. 35, n. 2, p. 207-227, 2010

MESQUITA, Rui. Teoria do discurso e análise de narrativa. In: ANAIS DO SEMINÁRIO INTERNACIONAL MÉTODOS QUALITATIVOS NAS CIÊNCIAS SOCIAIS E NA PRÁTICA SOCIAL. Anais... Recife: UFPE, 2006.

MORAES, Maria Célia de. "A teoria tem consequências": indagações sobre o conhecimento no campo da educação. Educação e Sociedade, Campinas, v. 30, n. 107, p. 585-607, maio/ago. 2009.

MORAES, Maria Célia de. Recuo na teoria: dilemas na pesquisa em educação. Revista Portuguesa de Educação, Braga, v. 14, n. 1, p. 7-25, 2001.

NORVAL, Aletta. Trajectories of future research in discourse theory. In: HOWARTH, David; NORVAL, Aletta; STAVRAKAKIS, Yannis (Org.). Discourse Theory and Political Analysis: Identities, hegemonies and social change. Manchester/New York: Manchester University, 2000.

OLIVEIRA, Anna Luiza. Tolerância, piedade, imposição? O discurso pela diversidade sexual (re)articulado por professores/as e gestores/as no cotidiano escolar. In: $1^{\circ}$ SEMINÁRIO INTERNACIONAL DE ESTUDOS CULTURAIS E EDUCAÇÃO - $4^{\circ}$ SEMINÁRIO BRASILEIRO DE ESTUDOS CULTURAIS E EDUCAÇÃO. Anais... Canoas: ULBRA, 2011.

OLIVEIRA, Anna Luiza; OLIVEIRA, Aurenéa; MIRANDA, Marcelo. Os estudos sobre gênero e diversidade sexual e as proposições da pedagogia queer para constituição de contextos escolares emancipatórios. Revista Educação em Questão, v. 44, n. 30, p. 110-138, 2013.

OLIVEIRA, Gustavo. Currículo, (pós-)secularismo e pluralismo religioso no Brasil. In: X COLÓQUIO SOBRE QUESTÕES CURRICULARES E VI COLÓQUIO LUSO-BRASILEIRO DE CURRÍCULO. Anais... Belo Horizonte: UFMG, 2012.

OLIVEIRA, Gustavo. Pluralismo e Novas Identidades no Cristianismo Brasileiro. 2009. $401 \mathrm{f}$. Tese (Doutorado em Sociologia) - Programa de Pós-graduação em Sociologia, Universidade Federal de Pernambuco, Recife, 2009.

PARAÍSO, Marlucy Alves. Pesquisas Pós-críticas em Educação no Brasil: esboço de um mapa. Cadernos de Pesquisa, São Paulo, v. 34, n. 122, p. 283-303, maio/ ago. 2004.

PEIRCE, Charles. Conferências sobre o pragmatismo. In: Os Pensadores: Peirce e Frege. São Paulo: Abril, 1983.

POPPER, Karl. A Lógica da Pesquisa Científica. São Paulo, Cultrix, 1980.

SALES JÚNIOR, Ronaldo. Hegemonia, hermenêutica e modelos matemáticos na teoria do discurso. In: WEBER, Silke; LEITHAUSER, Thomas (Org.). Métodos Qualitativos nas Ciências Sociais e na Prática Social. Recife: Editora da UFPE, 2007.

1348 Educação \& Realidade, Porto Alegre, v. 38, n. 4, p. 1327-1349, out./dez. 2013 Disponível em: <http://www.ufrgs.br/edu_realidade> 
SANTOS, Boaventura de Souza. Pela Mão de Alice. O social e o político na pósmodernidade. São Paulo: Cortez, 1997.

SANTOS, Boaventura de Souza. Introdução a uma Ciência Pós-moderna. Rio de Janeiro: Graal, 1989.

SHAPIRO, Ian. Problems, Methods, and Theories in the Study of Politics. Political Theory, v. 30, n. 4, pp. 596-619, 2002.

SHIPWAY, Brad. A Critical Realist Perspective of Education. Routledge: New York, 2011.

SILVA, Tomaz Tadeu da. Documentos de Identidade: uma introdução às teorias do currículo. Belo Horizonte: Autêntica, 1999.

SOUTHWELL, Myriam. Em Torno da Construção da Hegemonia Educativa: contribuições do pensamento de Ernesto Laclau ao problema da transmissão da cultura. In: MENDONÇA, Daniel; RODRIGUES, Léo. Pós-estruturalismo e Teoria do Discurso: em torno de Ernesto Laclau. Porto Alegre: EDPUCRS, 2008.

TORFING, Jacob. Discourse Theory: Achievements, Arguments, and Challenges. In: TORFING, Jacob; HOWARTH, David. Identity, Policy and Governance. New York: Palgrave, 2005.

VEIGA-NETO, Alfredo. Foucault e a Educação. Belo Horizonte: Autêntica, 2004. WARDE, Mirian. O Papel da Pesquisa na Pós-graduação em educação. Cadernos de Pesquisa, São Paulo, n. 73, p. 67-75, maio 1990.

ZIZEK, Slavoj. The Plague of Fantasies. London/New York: Verso, 2008.

ZIZEK, Slavoj. Más Allá del Análisis del Discurso. In: LACLAU, Ernesto. Nuevas Reflexiones Sobre la Revolución de Nuestro Tiempo. Buenos Aires: Nueva Visión, 2000.

Gustavo Gilson Oliveira é doutor em Sociologia, professor do Programa de Pós-Graduação em Educação Contemporânea do CAA/UFPE e do Departamento de Fundamentos Sócio-Filosóficos da Educação do CE/UFPE. Realiza estudos sobre Currículo, Teoria do Discurso e Identidades Religiosas. Participa do Coletivo Butuca, da Associação Brasileira de Currículo (ABdC) e do Grupo de Pesquisa Pós-estruturalismo, política e construção de identidades da UFPE.

E-mail: gustavosaet@yahoo.com.br

Anna Luiza Oliveira é professora do Programa de Pós-Graduação em Educação Contemporânea do CAA/UFPE e do Núcleo de Formação Docente do CAA/UFPE. Possui Doutorado em Educação e desenvolve trabalhos na área de Currículo, Teoria do Discurso, Diferença, Gênero e Sexualidade. Participa do Coletivo Butuca, da Associação Brasileira de Currículo (ABdC) e do Grupo de Pesquisa Pós-estruturalismo, política e construção de identidades da UFPE.

E-mail: alarmo@uol.com.br

Rui Gomes de Mesquita é doutor em Sociologia, professor do Programa de Pós-Graduação em Educação do CE/UFPE e do Departamento de Fundamentos Sócio-Filosóficos da Educação do CE/UFPE. Desenvolve trabalhos sobre Currículo, Teoria do Discurso, Educação Popular e Movimentos Sociais. É coordenador do Coletivo Butuca e membro do Grupo de Pesquisa Pós-estruturalismo, política e construção de identidades da UFPE.

E-mail: gomesdemattosdemesquita.rui@gmail.com

Educação \& Realidade, Porto Alegre, v. 38, n. 4, p. 1327-1349, out./dez. 2013 